\title{
University energy management improvement on basis of standards and digital technologies
}

\author{
Olga Novikova ${ }^{1, *}$, Svetlana Shirokova ${ }^{1}$, Anastasiia Tabakova $^{1}$ and Aleksandr Shadrin ${ }^{1}$ \\ ${ }^{1}$ Peter the Great St.Petersburg Polytechnic University, Polytechnicheskaya, 29, St. Petersburg, \\ 195251, Russia
}

\begin{abstract}
Nowadays to implement the energy management system it is important to fulfill not only the legal requirements but also to follow the set of recommendations prepared by international and national management standards. The purpose of this article is to prepare the concept and methodology for the optimization and improvement of the energy management system (EMS) for Universities with implementation of legal requirements and recommendations from international and national management standards with the help of digital technologies. During the research the systematic analysis, complex approach, logical sampling and analogy were used. It is shown that this process should be done with the help of the process-based approach, in accordance with ISO 9001, and energy management ISO 50001. The authors developed the structure of the basic standard of energy management: "Guidelines for the energy management system". It is proved that the involvement of the technical senior students in the project of EMS improvement allows to expand their competencies for new technics and technologies. Cloud service Bitrix24 was chosen for IT-support of the project. During the study, a list of characteristics was used as a basis for creating a query to the technology department of the university. DBMS Microsoft Access was chosen for its creation. In addition, the possible results of initiating a single database containing all the information needed for accounting and control of energy supply were listed. Moreover, the possibility of automated energy management system implementation and its results were considered. The required actions described in this research can be implemented in any University, that will extend energy management to any University worldwide.
\end{abstract}

\section{Introduction}

Nowadays the power efficiency increase in terms of energy management improvement is mainly performed by companies that receive certain economic effect out of it. These are companies that have high level of energy consumption and the significant share of the energy resources costs in the financial balance of the company. For universities this goal is not so economically significant, however, government requirements and the will to increase

\footnotetext{
*Corresponding author: novikova-olga1970@yandex.ru
} 
motivation of students for energy saving and energy efficiency increase enhances the significance of this goal. Therefore, in recent years, several legal, economic and organizational measures have been carried out to promote energy saving and improve energy efficiency in accordance with Russian Federal Law-261[1].

The main improvement trends of Universities activities in this sphere are determined in the Ministry Order of Education and Science of the Russian Federation from April 18, 2012 No. 309. According to this Ministry Order, personal responsibility for implementation of requirements of the Federal Law N 261-FL from November 23, 2011 is given to leaders of the organizations that are subordinated to the Ministry.

\section{Problem definition}

Today practical implementation of requirements from legal documents must be based on the international and national management standards concentrated in these documents. Besides the process approach must be the cornerstone of standards application management as the best theoretical ideas and practical results of systems improvement of the organizations arises from these standards [2].

In fact, it is difficult to imagine the management system without separately defined components (structure of the system). The definite purpose and the nature of activities within each component of the system (each division) should have action plan, realization tracker, control and improvement of the activities results. This is the process approach. These processes are specified as obligatory elements of any management system in the international standard of management processes: "The management system: a set of the interconnected and interacting elements of the organization required for the development of the policy, goals and processes for these goals achievement" [3].

Furthermore, energy saving is not a new task for Russian organizations including Universities: there have been legal documents defining requirements and recommendations in this sphere in Russia for many years. In the Universities there is always a special infrastructure with branched divisions responsible for energy supply to provide laboratory and household rooms with energy resources. These divisions are also responsible for monitoring of technical availability of provided power according to standardized requirements and optimization of economic characteristics. Therefore, starting implementation of the Legal requirements, a University mustn't set a task to "create" or "introduce", but to "improve" energy management system of the University based on Russian National Standard of International Organization for Standardization 50001 - 2012.

Currently, University infrastructure divisions are providing enough energy resources, but there is no unified system for accounting and monitoring of consumed and generated energy. Modern metering devices are installed selectively in some buildings of the universities, which makes it difficult to plan, normalize and evaluate the efficiency of consumption of fuel and energy resources, and more importantly, there is no possibility of describing the overall energy balance on the University territory. It is an extremely complex challenge to provide physical conditions for education and work with simultaneous increase in economic efficiency in Universities. This problem is common for all Universities in Russia and other countries [6].

\section{Problem solution}

To find possible solutions to this problem, a project was designed within Peter the Great Saint-Petersburg Polytechnic University. At firs the authors aimed to create a general description of the existing energy consumption system and heat energy generation system, 
which could later be used to optimize energy costs on all facilities of the university. The global goal of this project is to develop a mechanism for managing the energy saving and energy efficiency of the particular thermal zone on the example of one type of energy resource, which in turn will provide the basis for the introduction of a new automated system for controlling and accounting for energy resources (ASCAE). Moreover, one of the goals is to prepare a training and methodological base for students aimed at developing skills in achieving energy efficiency.

In the considered project, the solution of the problem of power efficiency increase was directed on the decrease of the cost index of the yearly spent energy resources per one student with unconditional fulfillment of sanitary standards in all educational, technical and household rooms. Besides the optimization of processes started with the functions regulation of the experts responsible for every process, without creation of new organizational structures. At the same time senior students were involved in terms of the internships and practical classes

Participation of students in this work allowed to fulfill such international standards requirements as the context of engineering education, introduction to engineering activity, experience of conducting design and implementation activity, working space of engineering activity, experience of the integrated training, active training [4].

At the beginning of the project on University EMS improvement it is important to receive support from the rector of the University and after that define corresponding tasks and the members of the working group on improvement of EMS.

For information support of project participants interaction, the Bitrix 24 system was chosen. Tools in Bitrix24 simplify the workflow in the organization: discussions, formulation and control of tasks, project management, etc. [5]. Within the framework of the project under consideration, this system facilitates simple and fast data exchange, allows you to exchange instant messages, schedule appointments and create tasks.

At the initial stage of the project, determined earlier goals were formulated, the stages of implementation were identified, and tasks were set for the near future. The primary task was the formation of the heat production consumers list and characteristics that are necessary for a comprehensive description of the system under consideration, such as: general information on the SPbPU boiler house for 2012-2014; data on boilers (general characteristics, fuel consumption, including gas and fuel oil); scheme of heat networks with all the necessary characteristics; Model of the heat supply zone; information on pumping equipment outside the boiler room; information on heat curtains; data on instrumental metering; quantity and cost of consumed heat production (common and separately for buildings) [7].

With the use of the Microsoft Access database, a query was generated on the above characteristics. It included several tables, in which each field was a separate characteristic. Each table was created in such a way that in the future it could be used in the final database with a minimum number of corrections.

Currently, the project is at the stage of collecting information and recording the data in the created request.

The characteristic feature of the considered project was the fact that at the time of improvement of EMS there was the quality management system (QMS) certified according to Russian National Standard International Organization for Standardization 9001-2011 in Universities and the text of the editorial office of ISO 9001-2015 was already known (and in the consequence of Russian National Standard of International Organization for Standardization 9001-2015). Therefore, the working group included a manager, responsible for certification of the management quality system along with specialists of technical, economic and scientific divisions. 
On the following step of provision the working group with the plan of works providing carrying out of certification of the first stage of EMS on compliance with Russian National Standard of International Organization for Standardization 50001 - 2012 were drafted.

One of the important requirements of the ISO 50001 that is described in the 4.4.3. and 4.6.1. paragraph is the importance of energy review, monitoring, measurement and analysis of energy resources consumption. As most of the universities' buildings were build more than 30 years ago most of them don't have modern systems for the control and analysis of the resources consumption, allowing to receive the detailed information for each building on the university campus for the specific period of time. This happens because when these buildings were designed and constructed there were no specific prescriptions for the control and analysis of the energy resources consumption by each building.

The authors carefully studied the measurement and analysis system of energy resources consumption on the example of the Peter the Great St. Petersburg polytechnic university. In the year 2016 expenses of the University for the utilities were $398860101 \mathrm{rub}$., out of which around 36\% are related to heating, that is approximately143589650 rub.

This is the reason why the authors focused specifically on the investigation of the heating system and revealed that on the entrance to the university buildings mainly the elevator pumps are installed, that are equipped only with thermometers while the technical registration units are missing. Therefore, the only possible way for the measurement of the heat consumption is the portable flowmeter.

To receive the correct data it is necessary to do the one-time measurements with the flowmeter on the entrances of the buildings, but the duration and the period of measurement should be equal, that is very inconvenient and expensive, as, for example, on the main campus of Peter the Great St. Petersburg polytechnic university there are 37 buildings. Moreover, to fill in the requirements of the ISO 50001 it is necessary to do the measurements regularly that will require a huge time wasting in the case of using the portable flowmeter.

As a solution of this problem the fixed meters can be used that will give an opportunity to collect the data for any required period of time, for example, hour, day, month, etc.

On the next development stage of the measurement and analysis of the energy resources consumption it is appropriate to implement the automated control and energy accounting systems that will allow to analyze the energy consumption automatically.

The same method for the measurement and analysis of the energy resources consumption can be used for the other types of resources, such as electrical energy, water supply, gas, etc.

The major task at improvement of EMS, as well as any other management system, is the development of new and updating of the existing documentation regulating activity within processes. The first new EMS document was "The guide to EMS". This Document included all basic provisions of University EMS fulfilling the requirements of ISO 50001:2012 standard and existing regulations of the University quality management system. The Document was prepared in terms of requirements of ISO 9001:2015 that is significantly different from the editorial from the ISO 900:2011.

The list of the sections of "The guide to EMS" of University is given below. In the annexes of the Document the reduced forms of the main legal documents applied to the energy management system of Universities according to the existing requirements of the public and municipal authorities are presented.

1 Application area

2 Normative references

3 Terms and definitions

4 The environment of the organization

4.1 Understanding the university and its environment 


\subsection{Structure}

4.3 Needs and expectations of the involved parties

4.4. The application area of the energy management system in the university

5 Leadership

4.5 Energy management system and its processes

5.1 Leadership and commitment

5.2 Policy

5.2.1 Development of energy policy

5.2.2 Enacting Energy Policy

6 Planning

5.3 Functions, responsibilities and authority in the organization

6.1 General regulations

6.2. Conformity with legal and other requirements

6.3. Energy analysis

6.4 Basic values of energy characteristics

6.5 Indicators of energy characteristics

6.6 Energy management goals and objectives

6.7 Planning for changes

7 Facilities of provision

7.1 Resources

7.1.1 General regulations

7.1.2 Human Resources

7.1.3 Infrastructure

7.1.4 Environment for the functioning of processes

7.1.5 Resources for monitoring and measurement

7.1.6 University knowledge

7.2 Competence of the staff

7.3 Staff awareness

7.4 Communication

7.5 Documented information

7.5.1 General regulations

7.5.2 Creation and actualization of documents

7.5.3 Management of documented information

8 Activities in the energy management system

9 Measurement of performance indicators

9.1 Monitoring, measurement, analysis and evaluation

9.1.1 General regulations

9.1.2 Assessment of compliance with legal and other regulatory requirements

9.1.3 Analysis and evaluation of the energy management system

9.2 Internal audit of the energy management system

9.3 Analysis of the energy management system from the leadership side

9.3.1 General regulations

9.3.2 Analysis of the input data from the leadership side

10 Improvement

9.3.3. Analysis of the output data from the leadership side

10.1 General regulations

10.2 Nonconformities and corrective actions

10.3 Constant improvement in the energy management system

Appendix 1 Energy policy

Appendix 2 The structure of the energy management system of the university 
Appendix 3 Responsibility matrix for effectuation of energy management processes

Appendix 4 List of documents of energy management system

Appendix 5 Form of the conclusion on the conclusion of the energy management system

Appendix 6 Form of opinion on the status of the energy management system

Appendix 7 Form of energy saving and energy efficiency program

Appendix 8 Form of action plan for the realization of the energy saving and energy efficiency program

Appendix 9 Information on indicators of energy efficiency of the university

Appendix 10 Report form (records) on the assessment of compliance of EMS with legal and other requirements

Appendix 11 Form of the report on the internal audit of the EMS

Appendix 12 The form of the journal of proposals for improving the EMS

As noted above, the improvement of the EMS is based on the process approach. The following list of processes is established for the first phase of the EMS university:

- Formation of energy policy

- Organization of EMS

- Heat supply management

- Electricity management

- Gas supply management

- Water supply management

- Internal audit

- Analysis of EMS by management

- Operational dispatching service

The Table 1 shows the form of the description of this process of the integrated management system, regulated by the university standards.

Table 1. Form for the description of processes.

\begin{tabular}{|c|c|c|}
\hline \multicolumn{3}{|c|}{ Process name } \\
\hline $\begin{array}{l}\text { Responsible for } \\
\text { the process }\end{array}$ & \multicolumn{2}{|c|}{ Process participant } \\
\hline who & \multicolumn{2}{|c|}{ who } \\
\hline \multicolumn{3}{|c|}{ Previous process } \\
\hline Responsible for receiving the result & Name & Responsible for passing the result on \\
\hline From which process & & Who is passing on \\
\hline \multicolumn{3}{|c|}{ Input of the present process } \\
\hline $\begin{array}{l}\text { Output of the previous process Input of the } \\
\text { present process }\end{array}$ & \multicolumn{2}{|r|}{ Responsible for the result receiving } \\
\hline Input & & Who is receiving \\
\hline \multicolumn{3}{|c|}{ Present process documentation } \\
\hline Regulatory documentation & & Totes (forms) during the process \\
\hline $\begin{array}{l}\text { The algorithm of changing the input into } \\
\text { the output }\end{array}$ & & notes are taken during the process \\
\hline
\end{tabular}




\begin{tabular}{|c|c|}
\hline \multicolumn{2}{|c|}{ Evaluation measure of the present process } \\
\hline What are the evaluation measures of the process \\
\hline Output of the present process \\
\hline Process output (the result) & Responsible for passing on \\
\hline What is the output & Who is passing on \\
\hline Name & Responsible for receiving \\
\hline What is the process & Who is receiving \\
\hline Control of passing on the results of the process \\
\hline Actions (control) during passing on & Notes during passing on \\
\hline $\begin{array}{c}\text { What actions (control) and by whom were } \\
\text { taken during passing on }\end{array}$ & What document identify the fact of passing on \\
\hline
\end{tabular}

\section{Conclusions}

As it was said earlier, the result of the project is the creation of a full-fledged digital database containing all the information that can be used for accounting and control of consumed and generated energy resources, as well as providing the possibility of calculating the required indicators. Keeping all information in a single database will simplify the process of monitoring energy supply and create prerequisites for the introduction of ASCAE.

After the completion of the required data collection, a number of criteria will be developed, on the basis of which the existing ASCAE will be compared and the most optimal option will be chosen.

The automated system for control and accounting of energy resources is a multichannel measuring system that performs in full or in part the execution of measuring and computational operations [8,9]. ASCAE quickly collects and processes the information necessary for managing energy supply. The introduction of such system will make it possible to optimize energy consumption, reduce heat losses and the amount of energy consumption, as well as to optimize energy-efficiency measures. Thus, it is possible to increase the energy efficiency of any University.

The implementation of the project on the description of the energy management system entails the expansion of opportunities for monitoring energy supply and can provide a basis for the implementation of the information system, which in turn will reduce the expenses of the educational institution $[8,10]$.

Practical requirements of the EMS Manual realization mean the creation of a management integrated system, which meets two state standards - GOST (GOST - State Standard, Russian National Standard) R ISO 9001 and GOST R ISO 50001. The students' participation during the process of development and further monitoring of energy management system allows to widen competence of students.

Authors are grateful to E.A. Timchenko for the assistance in project implementation.

\section{References}

1. M. Schulze, H. Nehler, M. Ottosson, P. Thollander, Journal of Cleaner Production 112, 3692-3708 (2016)

2. O. Novikova, A. Shadrin, Processnyj podhod v ehnergetiche-skommenedzhmente 8, 70-73 (2014) 
3. ISO/IEC Directives, Part 1. Consolidated ISO Supplement - Procedures specific to ISO (2012)

4. N. Yang, Exploring College Students' Perceptions of Internship Experience (2016)

5. V. Volkova, A. Loginova, S. Shirokova, E. Iakovleva, 19th IEEE, SCM 2017 7519831, 515-517 (2017)

6. E. Kuznetsov, O. Novikova, A. Dyachenko, Economy and management of conservation of energy, 600 (2011)

7. V. Volkova, A. Loginova, S. Shirokova, E. Kozlovskay, 19th IEEE, SCM 2017 7519825, 497-499 (2016)

8. RD 34.11.114-98 Automated systems for monitoring and accounting of electricity and capacity

9. A. Grinev, O. Novikova, S. Lozovsky, Scientific and technical statements SPbSPU 1, 54 (2015)

10. D. Dybok, A. Mochalova, S. Shirokova. Week of Science of SPbPU materials of the scientific-practical conference. Engineering and Economics Institute of SPbPU, 199202 (2015) 